\title{
X-ray fluorescence mapping: Insights into mesoscale structure impact on battery functional electrochemistry
}

\author{
Nahian Sadique ${ }^{1,2} \cdot$ Steven T. King ${ }^{1,2} \cdot$ Genesis D. Renderos ${ }^{1,2} \cdot$ Christopher J. Kern $^{1,2} \cdot$ Lisa M. Housel ${ }^{1,4}$. \\ Kenneth J. Takeuchi ${ }^{1,2,4} \cdot$ Esther S. Takeuchi ${ }^{1,2,3,4} \cdot$ Amy C. Marschilok $^{1,2,3,4}$
}

Received: 28 September 2021 / Accepted: 24 October 2021 / Published online: 19 November 2021

(c) The Author(s) 2021

\begin{abstract}
Electron transfer and ion transport occurs over multiple-length scales ranging from the atomic to mesoscale within battery materials and electrodes. Micro-X-ray fluorescence $(\mu-X R F)$ is an important characterization tool as it can resolve structural, compositional, and redox information while providing insight into the spatial distribution of an electroactive material. In this work, $\mu$-XRF mapping is used to probe the distribution of iron within thin planar slurry-based and thick porous carbon nanotube $(\mathrm{CNT})$-based magnetite $\left(\mathrm{Fe}_{3} \mathrm{O}_{4}\right)$ electrodes. Notably, the porous CNT-based electrode showed homogenous distribution of $\mathrm{Fe}$ within the electrode whereas the planar electrode demonstrated distinct Fe aggregates. This information was used to rationalize the electrochemistry observed by cyclic voltammetry and galvanostatic cycling. The thick porous electrode delivered $215 \%$ more capacity per gram of magnetite during the first discharge, consistent with increased electrode homogeneity enabling effective ion access and electron transfer.
\end{abstract}

\section{Introduction}

Understanding the ion and electron transport mechanisms within batteries is important to developing next-generation technologies [1]. While the active materials are crucial and determine the theoretical energy content and voltage of the devices [2], electrode design factors can significantly impact electrochemical function [3]. Using a tightly-focused primary $\mathrm{X}$-ray beam to induce $\mathrm{X}$-ray fluorescence emission as a sample is scanned, micro-X-ray fluorescence ( $\mu$-XRF) enables spatially resolved characterization of metal centers

Kenneth J. Takeuchi

kenneth.takeuchi.1@stonybrook.edu

Esther S. Takeuchi

esther.takeuchi@stonybrook.edu

$\triangle$ Amy C. Marschilok

amy.marschilok@stonybrook.edu

1 Institute for Electrochemically Stored Energy, Stony Brook University, Stony Brook, NY 11794, USA

2 Department of Chemistry, Stony Brook University, Stony Brook, NY 11794, USA

3 Department of Materials Science and Chemical Engineering, Stony Brook University, Stony Brook, NY 11794, USA

4 Interdisciplinary Science Department, Brookhaven National Laboratory, Upton, New York 11973, USA and their oxidation states [4]. Synchrotron light sources are desirable for $\mu$-XRF due to their high X-ray intensity, although benchtop and even portable solutions have been reported [5, 6].

This report focuses on use of $\mu$-XRF mapping for characterization of magnetite $\left(\mathrm{Fe}_{3} \mathrm{O}_{4}\right)$ electrodes. $\mathrm{Fe}_{3} \mathrm{O}_{4}$ is a naturally abundant, non-toxic iron oxide material with a theoretical capacity of $926 \mathrm{mAh} / \mathrm{g}, \sim 3 \times$ that of graphite $(\sim 372$ $\mathrm{mAh} / \mathrm{g}$ ) [7] and is thus an attractive material for lithium ion battery anodes. Unlike graphite, $\mathrm{Fe}_{3} \mathrm{O}_{4}$ electrodes undergo a multi-step electrochemical reduction, beginning with $\mathrm{Li}^{+}$ insertion into the host spinel structure and ending with conversion reactions to $\mathrm{FeO}$ and $\mathrm{Fe}^{0}[8,9]$. The first lithium equivalent inserts into an interstitial octahedral (16c) site. The second lithium equivalent inserts into the $\mathrm{Fe}_{3} \mathrm{O}_{4}$ lattice, displacing the $\mathrm{Li}^{+}$already situated in $16 \mathrm{c}$ sites while the two $\mathrm{Li}^{+}$are redistributed between $8 \mathrm{a}, 48 \mathrm{f}$ and $8 \mathrm{~b}$ interstitial tetrahedral sites. The third and fourth lithium equivalents result in formation of $\mathrm{Li}_{2} \mathrm{O} \cdot \mathrm{FeO}$ and then $\mathrm{Fe}^{0}$ metal, where the overall half-reaction for $\mathrm{Fe}_{3} \mathrm{O}_{4}$ is:

$\mathrm{Fe}_{3} \mathrm{O}_{4}+8 \mathrm{Li}^{+}+8 \mathrm{e}^{-} \rightarrow 3 \mathrm{Fe}^{0}+4 \mathrm{Li}_{2} \mathrm{O}$.

$\mathrm{Fe}_{3} \mathrm{O}_{4}$ crystallite size has been shown to significantly influence the electrochemistry due to changes in the length of the lithium ion diffusion path [4, 8, 10-12]. $\mu$-XRF mapping provided important findings on the charge transport 
within thin planar $\mathrm{Fe}_{3} \mathrm{O}_{4}$ electrodes prepared with different crystallite sized material where electrodes prepared with $12 \mathrm{~nm} \mathrm{Fe}_{3} \mathrm{O}_{4}$ showed increased $\mathrm{Fe}$ aggregation relative to $30 \mathrm{~nm} \mathrm{Fe}{ }_{3} \mathrm{O}_{4}$ electrodes. Complimentary X-ray absorption near edge spectroscopy (XANES) analysis indicated greater reduction of smaller Fe aggregates within the $30 \mathrm{~nm}$ electrode, which correlated with decreased total heat generation measured by isothermal microcalorimetry [13]. X-ray absorption spectroscopy has been used to follow the lithiation and electrochemical reduction of $\mathrm{Fe}_{3} \mathrm{O}_{4}$, with complementary density functional theory (DFT) to elucidate the four species involved in the whole intercalation-conversion process of $\mathrm{Fe}_{3} \mathrm{O}_{4}$ [14].

An alternative approach toward designing high energy, high power batteries is fabrication of three-dimensional thick porous electrodes that facilitate ion transport. Electroactive materials can be incorporated into carbon based substrates to achieve desirable mechanical and electrochemical properties. Recently, carbon nanofibers impregnated with $\mathrm{Fe}_{3} \mathrm{O}_{4}$ nanoparticles (NPs) were shown to function as flexible and high capacity negative electrodes for lithiumion batteries, achieving a initial high discharge capacity of $1146 \mathrm{mAh} / \mathrm{g}$ [15]. Carbon nanotube (CNT) substrates can provide multiple advantages including increased electrical conductivity and strong $\mathrm{sp}^{2}$ hybridization to buffer volumetric changes of conversion lithiation reactions [3]. Operando energy dispersive $\mathrm{X}$-ray diffraction (EDXRD) demonstrated $\mathrm{Fe}_{3} \mathrm{O}_{4}$ lithiation can progress homogenously throughout $\mathrm{Fe}_{3} \mathrm{O}_{4}-\mathrm{CNT}$ electrodes, indicating effective electronic and ionic transport [16].

In this work, $\mu$-XRF mapping was applied to determined Fe dispersion within traditional, planar slurry-based and thick porous $\mathrm{CNT}$-based $\mathrm{Fe}_{3} \mathrm{O}_{4}$ electrodes. The goal was to compare the mesoscale structure of a conventional electrode (coated foil) prepared using the state of the art manufacturing process, to a new electrode type (3D porous electrode) prepared using a lower manufacturing readiness fabrication technique. Cyclic voltammetry (CV) and galvanostatic cycling tests were performed to compare the electrochemistry of the two electrode constructs.

\section{Materials and Methods}

$\mathrm{Fe}_{3} \mathrm{O}_{4}$ NPs were synthesized by oxidizing a basic $\mathrm{FeCl}_{2}$ solution in air for $12 \mathrm{~h}$ adapted from a previously reported method [13]. Electron microscopy imaging of these $\mathrm{Fe}_{3} \mathrm{O}_{4}$ NPs has been provided previously [8,9]. The sample was washed via centrifugation using water and freeze-dried overnight. X-ray powder diffraction (XRD) patterns were collected using a Rigaku smart lab X-ray powder diffractometer with Bragg-Brentano focusing geometry and $\mathrm{Cu} \mathrm{K} \alpha$ radiation $(\lambda=1.5406 \AA)$. Crystallite size was calculated using the
Scherrer equation based on the full-width half-maximum of the 220 diffraction peak after correcting for instrumental broadening using a lanthanum hexaboride standard [17]. Crystallite size was also determined via Rietveld refinement using GSAS-II [18].

CNT-based electrodes were prepared with $\mathrm{Fe}_{3} \mathrm{O}_{4}$ and CNTs in a 6:4 mass ratio. Thin planar electrodes were prepared by mixing $\mathrm{Fe}_{3} \mathrm{O}_{4}$ (42.5\%), carbon (42.5), and polyvinylidene difluoride binder $(15 \%)$ with $N$-methyl2-pyrrolidone (NMP) and casting onto copper foil. Synchrotron-based X-ray fluorescence mapping of the pristine electrodes was collected at the SRX Beamline (5ID) within the National Synchrotron Light Source (NSLS-II) at Brookhaven National Laboratory. The $100 \times 100 \mu \mathrm{m}$ maps were collected using a step size of $2 \mu \mathrm{m}$ and $65 \mathrm{~mm}$ detector distance. Energy was tuned with a double-crystal monochromator and fluorescence intensity detected using a three-element Vortex ME3 silicon drift detector. During the maps, the monochromator was tuned to $7200 \mathrm{eV}$. Calibration was executed with a Fe reference foil. ImageJ software was utilized measure size of $\mathrm{Fe}$ aggregates within the maps [19].

Coin type cells were fabricated with the $\mathrm{Fe}_{3} \mathrm{O}_{4}$ electrodes, lithium metal anodes, $1 \mathrm{M} \mathrm{LiPF}_{6} \mathrm{EC}_{\mathrm{DMC}}(3 / 7 \mathrm{v} / \mathrm{v})$ electrolyte, and polypropylene separators. $\mathrm{CV}$ was conducted at $0.1 \mathrm{mV} / \mathrm{s}$ between 0.5 and $2.8 \mathrm{~V}$ for five cycles using a Biologic VSP potentiostat at $30{ }^{\circ} \mathrm{C}$. Extended cycling tests using a constant current of $100 \mathrm{~mA} / \mathrm{g}$ or $400 \mathrm{~mA} / \mathrm{g}$ were executed using a Maccor battery tester at $30{ }^{\circ} \mathrm{C}$ from 0.3 to $3.0 \mathrm{~V}$ [20]. The average mass loadings for the thin and thick electrodes were 1.25 and $3.72 \mathrm{mg} / \mathrm{cm}^{2}$, respectively.

\section{Results}

Rietveld refinement of the XRD pattern confirmed a $F d \overline{3} m$ space group for the as-synthesized material group (Fig. S1; Table 1), consistent with the inverse spinel structure. A crystallite size of $30 \mathrm{~nm}$ was determined by the Scherrer equation.

$\mu$-XRF mapping is an element specific technique used here to understand the spatial arrangement of Fe electroactive material within planar and CNT-based electrodes. Notably, the CNT-based electrodes $(120 \mu \mathrm{m})$ are thicker than the planar $(35 \mu \mathrm{m})$ electrodes, and thus, display significantly higher raw, absolute XRF intensities. Therefore, the $\mu$-XRF maps of the two electrodes were compared using the same relative intensity range, rather than absolute XRF intensity. $\mu$-XRF maps of the planar slurry-cast electrode (Fig. 1a) demonstrated clear regions of $\mathrm{Fe}$ aggregation; whereas, the $\mathrm{Fe}$ signal was more dispersed throughout $\mathrm{Fe}_{3} \mathrm{O}_{4}-\mathrm{CNT}$ electrode (Fig. 2b), indicating increased homogeneity. Fe aggregate size was estimated by measuring the maximum distance of a visualized aggregate, which is denoted in Fig. 1c as 

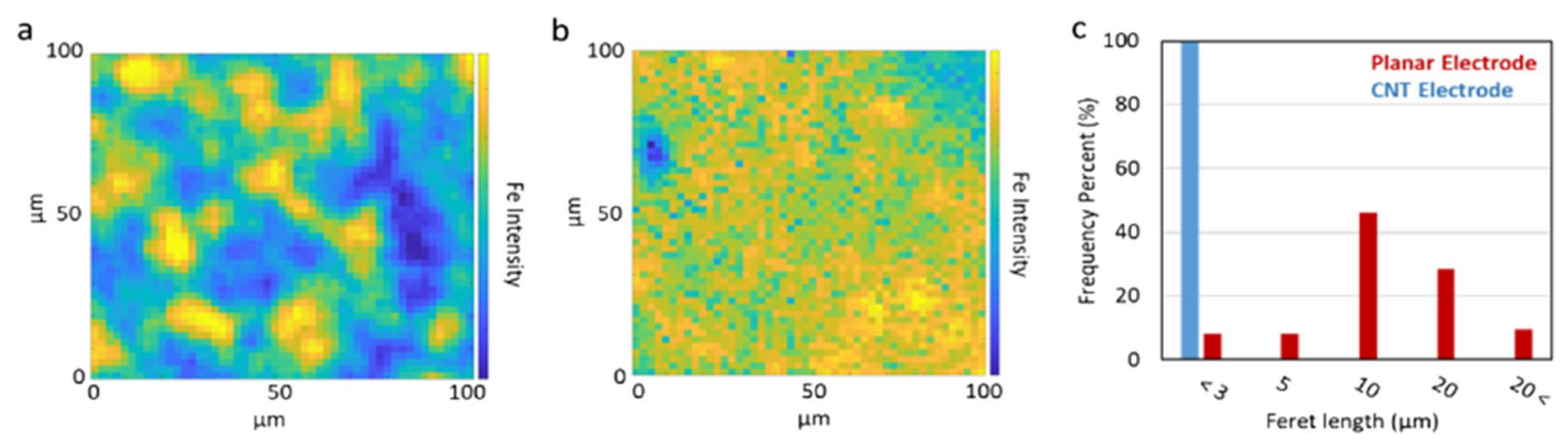

Fig. $1 \mu$-XRF mapping of a planar and $\mathbf{b} \mathrm{CNT}-\mathrm{Fe}_{3} \mathrm{O}_{4}$ electrodes. $\mathbf{c}$ Size distribution of aggregates
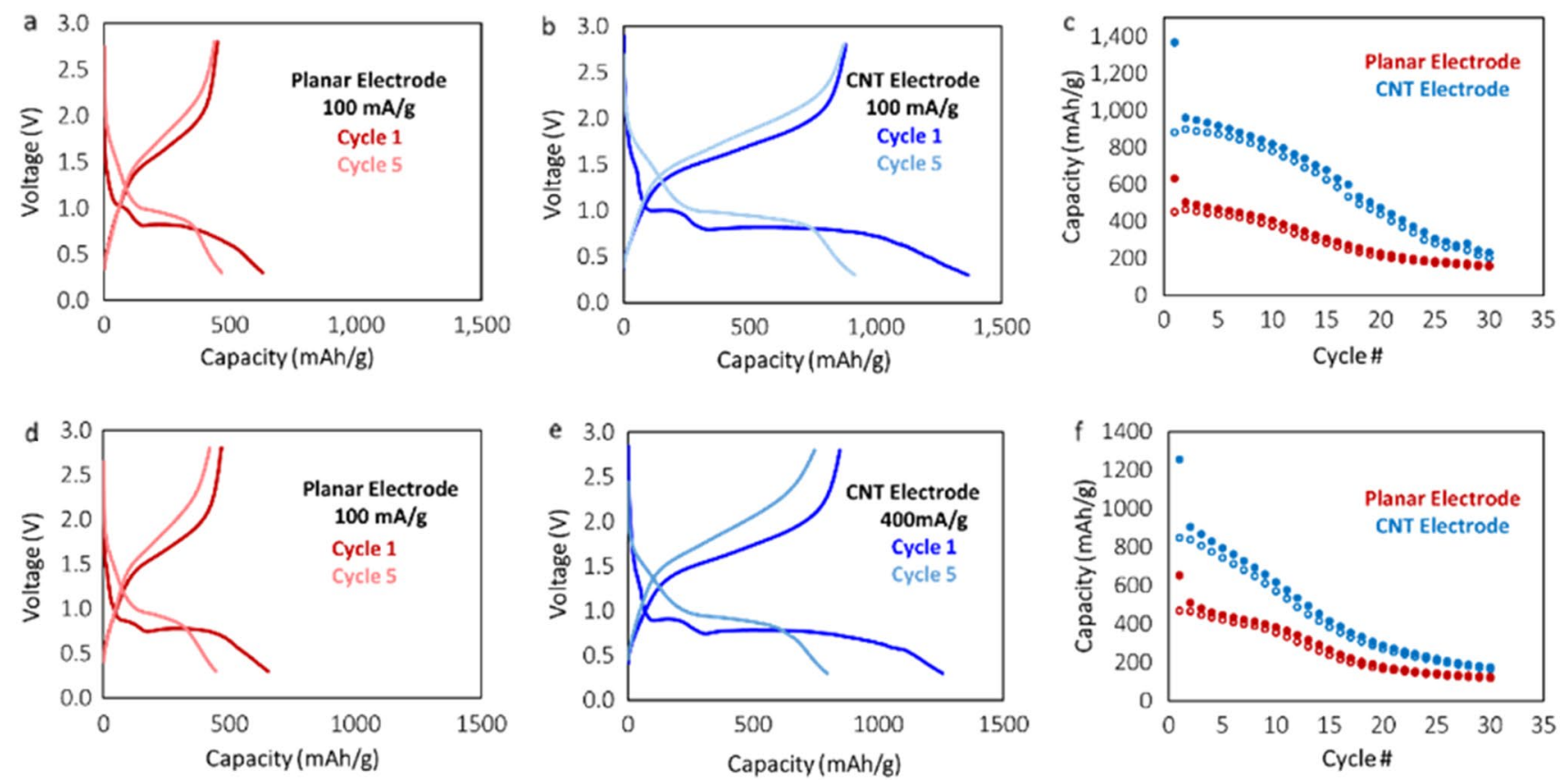

Fig. 2 Cycles 1 and 5 voltage profiles for the a, d planar and b,e CNT electrodes collected at a, b $100 \mathrm{~mA} / \mathrm{g}$ and d, e $400 \mathrm{~mA} / \mathrm{g}$. Discharge (closed circles) and charge (open circles) capacities as a func-

Feret length. Aggregate size distributions of the planar and CNT electrodes (Fig. 1c) showed larger Fe aggregates within the planar electrode and smaller aggregates in the CNT electrode, indicating increased homogeneity of the $\mathrm{Fe}_{3} \mathrm{O}_{4}$ electroactive material within the CNT design.

$\mathrm{CV}$ at $0.1 \mathrm{mV} / \mathrm{s}$ from 0.5 to $2.8 \mathrm{~V}$ was collected for five cycles to understand the reduction and oxidation mechanisms of planar (Fig. S2a) and CNT (Fig. S2b) $\mathrm{Fe}_{3} \mathrm{O}_{4}$ electrodes. During the first reduction, the both cell types showed three peaks at $\sim 1.5 \mathrm{~V}, 1.0 \mathrm{~V}$, and $0.5-0.7 \mathrm{~V}$, indicating similar $\mathrm{Fe}_{3} \mathrm{O}_{4}$ reduction mechanism, consistent with the $\mathrm{Li}^{+}$insertion, $\mathrm{FeO}$ conversion and $\mathrm{Fe}^{0}$ conversion reactions, respectively [9]. Notably, the CNT electrode generated tion of cycle number for the planar (red) and CNT (blue) $\mathrm{Fe}_{3} \mathrm{O}_{4}$ electrodes at c $100 \mathrm{~mA} / \mathrm{g}$ and $\mathbf{f} 400 \mathrm{~mA} / \mathrm{g}$

more mass normalized current during the $\mathrm{FeO}$ to $\mathrm{Fe}^{0}$ conversion reaction at $0.5 \mathrm{~V}$ to $0.7 \mathrm{~V}$, which may be attributed to decreased $\mathrm{Fe}_{3} \mathrm{O}_{4}$ aggregation within the electrode. During oxidation, the broad, two-peak feature from 1.5 to $2.0 \mathrm{~V}$, indicates the oxidation of $\mathrm{Fe}^{0}$ metal to the $\mathrm{FeO}$ rocksalt-like phase [9]. Upon cycles $2-5$, one cathodic peak was identified at $1.0 \mathrm{~V}$, consistent with a reduction of the $\mathrm{FeO}$ rock-salt structure back to $\mathrm{Fe}^{0}$. Both electrode designs demonstrated that the spinel structure was not recovered on delithiation.

Figure 2 compares the extended constant current cycling of $\mathrm{Li} / \mathrm{Fe}_{3} \mathrm{O}_{4}$ cells containing the planar and $\mathrm{CNT}-\mathrm{Fe}_{3} \mathrm{O}_{4}$ electrodes. Figure $2 \mathrm{a}-\mathrm{c}$ were collected at a $100 \mathrm{~mA} / \mathrm{g}$ current over 30 cycles while the data shown in Fig. 2d-f were 
collected at a higher current of $400 \mathrm{~mA} / \mathrm{g}$. Voltage profiles for cycles 1 and 5 are shown for each current as a function of capacity. In the initial lithiation, both the planar and CNT electrodes demonstrated three voltage plateaus at $1.5 \mathrm{~V}$, $1.0 \mathrm{~V}$ and $0.5 \mathrm{~V}$, consistent with the CV results (Fig. S2). At the $100 \mathrm{~mA} / \mathrm{g}$ rate, the planar electrode cells delivered 630 $\mathrm{mAh} / \mathrm{g}$ upon lithiation to $0.3 \mathrm{~V}$ (Fig. 2a); while the CNT electrode delivered $1366 \mathrm{mAh} / \mathrm{g}$ (Fig. 2b). By cycle 5, the CNT electrodes reached a discharge capacity of $901 \mathrm{mAh} / \mathrm{g}$, while the planar electrodes maintained a capacity of 468 $\mathrm{mAh} / \mathrm{g}$. The capacity retention after 30 cycles at $100 \mathrm{~mA} / \mathrm{g}$ was $25 \%$ and $17 \%$ for the planar and CNT electrodes, respectively (Fig. 2c) indicating that both electrode architectures experienced capacity decreases on cycling. At the $400 \mathrm{~mA} / \mathrm{g}$ rate, the first lithiation capacity for the planar electrode was $652 \mathrm{mAh} / \mathrm{g}$ (Fig. 2d) and the CNT electrode delivered 1256 $\mathrm{mAh} / \mathrm{g}$ (Fig. 2e), suggesting an increase in rate does not significantly change first lithiation capacities for either the planar or CNT electrode. By cycle 5, the CNT electrodes reached a discharge capacity of $794 \mathrm{mAh} / \mathrm{g}$, while the planar electrodes maintained a capacity of $446 \mathrm{mAh} / \mathrm{g}$. After 30 cycles at $400 \mathrm{~mA} / \mathrm{g}$, the planar and CNT electrodes retained $18 \%$ and $13 \%$ capacity, respectively.

\section{Discussion}

In this report, $\mu$-XRF mapping was collected on planar and $\mathrm{CNT}-\mathrm{Fe}_{3} \mathrm{O}_{4}$ electrodes to elucidate the distribution of the $\mathrm{Fe}_{3} \mathrm{O}_{4}$ electroactive material within different electrode constructs. The CNT electrodes showed increased Fe homogeneity; whereas, the planar electrode showed clear regions of high Fe intensity, indicating aggregation. Statistical analysis of the $\mathrm{Fe} K$-edge maps clearly demonstrated larger aggregate sizes within the planar electrode. CV indicated the initial reduction processes of the two electrodes were comparable, where three peaks present in initial cathodic scans, consistent with known lithium insertion and conversion reactions. Galvanostatic cycling results demonstrated significant differences between the planar and CNT electrodes, where the CNT electrode delivered $215 \%$ more capacity during cycle 1 lithiation at $100 \mathrm{~mA} / \mathrm{g}$ and $400 \mathrm{~mA} / \mathrm{g}$ rates consistent with decreased agglomeration observed by the $\mu$-XRF mapping. Thus $\mu$-XRF provides effective characterization of active material distributions and is well-suited for synergistic investigations that couple electrochemistry and other X-ray methods such XANES

Supplementary Information The online version contains supplementary material available at https://doi.org/10.1557/s43580-021-00150-w.

Acknowledgements The authors acknowledge the Center for Mesoscale Transport Properties, an Energy Frontier Research Center supported by the U.S. Department of Energy, Office of Science, Basic
Energy Sciences, under Award \#DE-SC0012673 for financial support. The $\mu$-XRF maps were collected at National Synchrotron Light Source II, Brookhaven National Laboratory, which is supported by the Department of Energy, under Contract No. DE-SC0012704. EST acknowledges the support as the William and Jane Knapp Chair of Energy and the Environment.

Data Availability Relevant data will be made available upon reasonable request to the corresponding authors.

\section{Declarations}

Conflict of interest The authors declare no conflicts of interest.

Open Access This article is licensed under a Creative Commons Attribution 4.0 International License, which permits use, sharing, adaptation, distribution and reproduction in any medium or format, as long as you give appropriate credit to the original author(s) and the source, provide a link to the Creative Commons licence, and indicate if changes were made. The images or other third party material in this article are included in the article's Creative Commons licence, unless indicated otherwise in a credit line to the material. If material is not included in the article's Creative Commons licence and your intended use is not permitted by statutory regulation or exceeds the permitted use, you will need to obtain permission directly from the copyright holder. To view a copy of this licence, visit http://creativecommons.org/licenses/by/4.0/.

\section{References}

1. J. Goodenough, Y. Kim, Challenges for rechargeable Li batteries. Chem. Mater. 22, 587 (2010)

2. N. Nitta, F. Wu, J.T. Lee, G. Yushin, Li-ion battery materials: present and future. Mater. Today 18, 252 (2015)

3. Y. Wu, J. Wang, K. Jiang, S. Fan, Applications of carbon nanotubes in high performance lithium ion batteries. Front. Phys. 9, 351 (2014)

4. D.C. Bock, C.J. Pelliccione, W. Zhang, J. Wang, K.W. Knehr, J. Wang, F. Wang, A.C. West, A.C. Marschilok, K.J. Takeuchi, E.S. Takeuchi, Dispersion of nanocrystalline $\mathrm{Fe}_{3} \mathrm{O}_{4}$ within composite electrodes: insights on battery-related electrochemistry. ACS Appl. Mater. Interfaces 8, 11418 (2016)

5. E.S. Rodrigues, M.H.F. Gomes, N.M. Duran, J.G.B. Cassanji, T.N.M. da Cruz, A. Sant'Anna Neto, S.M. Savassa, E. de Almeida, H.W.P. Carvalho, Laboratory microprobe X-ray fluorescence in plant science: emerging applications and case studies. Front. Plant Sci. 9, 1588 (2018)

6. F. Lopes, R.J.C. Silva, M.F. Araújo, V.H. Correia, L. Dias, J. Mirão, Micro-EDXRF, SEM-EDS and OM characterisation of tin soldering found in handle attachments of Roman situlae from Conimbriga (Portugal). Microchem. J. 138, 438 (2018)

7. D.C. Bock, G.H. Waller, A.N. Mansour, A.C. Marschilok, K.J. Takeuchi, E.S. Takeuchi, Investigation of solid electrolyte interphase layer formation and electrochemical reversibility of magnetite, $\mathrm{Fe}_{3} \mathrm{O}_{4}$, electrodes: a combined X-ray absorption spectroscopy and X-ray photoelectron spectroscopy study. J. Phys. Chem. C 122, 14257 (2018)

8. D.C. Bock, C.J. Pelliccione, W. Zhang, J. Timoshenko, K.W. Knehr, A.C. West, F. Wang, Y. Li, A.I. Frenkel, E.S. Takeuchi, K.J. Takeuchi, A.C. Marschilok, Size dependent behavior of $\mathrm{Fe}_{3} \mathrm{O}_{4}$ crystals during electrochemical (de)lithiation: an in situ X-ray diffraction, ex situ X-ray absorption spectroscopy, transmission 
electron microscopy and theoretical investigation. Phys. Chem. Chem. Phys. 19, 20867 (2017)

9. W. Zhang, D.C. Bock, C.J. Pelliccione, Y. Li, L. Wu, Y. Zhu, A.C. Marschilok, E.S. Takeuchi, K.J. Takeuchi, F. Wang, Insights into ionic transport and structural changes in magnetite during multiple-electron transfer reactions. Adv. Energy Mater. 6, 1502471 (2016)

10. K.W. Knehr, N.W. Brady, C.A. Cama, D.C. Bock, Z. Lin, C.N. Lininger, A.C. Marschilok, K.J. Takeuchi, E.S. Takeuchi, A.C. West, Modeling the mesoscale transport of lithium-magnetite electrodes using insight from discharge and voltage recovery experiments. J. Electrochem. Soc. 162, A2817 (2015)

11. S. Zhu, A.C. Marschilok, E.S. Takeuchi, K.J. Takeuchi, Crystallite size control and resulting electrochemistry of magnetite, $\mathrm{Fe}_{3} \mathrm{O}_{4}$. Electrochem. Solid State Lett. 12, A91 (2009)

12. S. Zhu, A.C. Marschilok, E.S. Takeuchi, G.T. Yee, G. Wang, K.J. Takeuchi, Nanocrystalline magnetite: synthetic crystallite size control and resulting magnetic and electrochemical properties. J. Electrochem. Soc. 157, A1158 (2010)

13. M.M. Huie, D.C. Bock, A.M. Bruck, K.R. Tallman, L.M. Housel, L. Wang, J. Thieme, K.J. Takeuchi, E.S. Takeuchi, A.C. Marschilok, Isothermal microcalorimetry: insight into the impact of crystallite size and agglomeration on the lithiation of magnetite, $\mathrm{Fe}_{3} \mathrm{O}_{4}$. ACS Appl. Mater. Interfaces 11, 7074 (2019)

14. C. Nayak, N. Abharana, B. Modak, K. Halankar, S.N. Jha, D. Bhattacharyya, Insight into the charging-discharging of magnetite electrodes: in situ XAS and DFT study. Phys. Chem. Chem. Phys. 23, 6051 (2021)

15. C.A. Velasquez, F.A. Vasquez, M. Alvarez-Lainez, A. ZapataGonzalez, J.A. Calderon, Carbon nanofibers impregnated with $\mathrm{Fe}_{3} \mathrm{O}_{4}$ nanoparticles as a flexible and high capacity negative electrode for lithium-ion batteries. J. Alloys Compd. 862, 158045 (2021)

16. A.M. Bruck, L. Wang, A.B. Brady, D.M. Lutz, B.L. Hoff, K. Li, N. Stavinski, D.C. Bock, K.J. Takeuchi, E.S. Takeuchi, A.C. Marschilok, Energy-dispersive X-ray diffraction: operando visualization of electrochemical activity of thick electrodes. J. Phys. Chem. C 123, 18834 (2019)

17. A. Monshi, M.R. Foroughi, M. Monshi, Modified Scherrer equation to estimate more accurately nano-crystallite size using XRD. World J. Nano Sci. Eng. 2, 154 (2012)

18. B. Toby, R. Dreele, GSAS-II: the genesis of a modern open-source all-purpose crystallography software package. J. Appl. Crystallogr. 46, 544 (2013)

19. C.A. Schneider, W.S. Rasband, K.W. Eliceiri, NIH Image to ImageJ: 25 years of image analysis. Nat. Methods 9, 671 (2012)

20. L. Wang, Y. Li, J. Li, S. Zou, E. Stach, K. Takeuchi, E. Takeuchi, A. Marschilok, S. Wong, Correlating preparative approaches with electrochemical performance of $\mathrm{Fe}_{3} \mathrm{O}_{4}-\mathrm{MWNT}$ composites used as anodes in li-ion batteries. ECS J. Solid State Sci. Technol. 6, M3122 (2017) 